\title{
Numerical modelling of GPR electromagnetic fields for locating burial sites
}

\author{
José M. Carcione ${ }^{1}$, Jerzy Karczewski ${ }^{2}$, Ewelina Mazurkiewicz ${ }^{2}$, Ryszard Tadeusiewicz ${ }^{2}$, \\ and Sylwia Tomecka-Suchon ${ }^{2 *}$ \\ ${ }^{1}$ Istituto Nazionale di Oceanografia e di Geofisica Sperimentale OGS, 34010 Trieste, Italy \\ ${ }^{2}$ AGH University of Science and Technology, 30-059 Krakow, Poland
}

\begin{abstract}
Ground-penetrating radar (GPR) is commonly used for locating burial sites. In this article, we acquired radargrams at a site where a domestic pig cadaver was buried. The measurements were conducted with the ProEx System GPR manufactured by the Swedish company Mala Geoscience with an antenna of $500 \mathrm{MHz}$. The event corresponding to the pig can be clearly seen in the measurements. In order to improve the interpretation, the electromagnetic field is compared to numerical simulations computed with the pseudo-spectral Fourier method. A geological model has been defined on the basis of assumed electromagnetic properties (permittivity, conductivity and magnetic permeability). The results, when compared with the GPR measurements, show a dissimilar amplitude behaviour, with a stronger reflection event from the bottom of the pit. We have therefore performed another simulation by decreasing the electrical conductivity of the body very close to that of air. The comparison improved, showing more reflections, which could be an indication that the body contains air or has been degraded to a certain extent that the electrical resistivity has greatly increased.
\end{abstract}

\section{Introduction}

In this work, the possibility of locating burial sites on the basis of GPR radargrams is analysed. An extensive introduction to the method can be found, among others, in the following works: [1 - 5]. Carcione [6,7], illustrate the method and the related theory for detecting contaminated sites and coffins, respectively. The search of burial sites with the GPR was described by Doolittle and Bellantoni [8] and Schultz [9], among others. Apart from the GPR technique, other geophysical methods can be used to locate graves, for instance, electrical methods [10,11] and magnetometry [12].

The target here is a domestic pig cadaver (Sus Scofa Domestica) buried in south-eastern Poland. The pit bottom is located at approximately $1 \mathrm{~m}$ depth, and for the purposes of modelling, the cadaver cross-section dimensions are assumed to be $1 \mathrm{~m} \times 0.5 \mathrm{~m}$. Clay and loamy sand are predominant in the place of the measurement. A set of GPR profiles were

\footnotetext{
*Corresponding author: tomecka@agh.edu.pl
} 
acquired, the aim of which is to assess the suitability of the technique at burial sites with difficult geological conditions (clay and loamy sand with high attenuation of electromagnetic waves).

In specific cases, in order to solve ambiguity during GPR interpretation, numerical modelling of the electromagnetic wave field was used. In the paper by Golebiowski [13] numerical modelling was applied for proper interpretation of radargrams recorded in river dike; in the paper by Golebiowski [14] the synthetic radargrams were used to improve the interpretation of GPR data recorded in archaeological site; in paper by Marcak and Golebiowski [15] numerical modelling of two-phase flow and electromagnetic wave field were applied for proper interpretation of radargrams recorded in hydrocarbon contaminated sites. In the paper a modelling algorithm based on the pseudo-spectral Fourier method has been employed and the results compared with the radargram recorded by a ProEx System GPR with a 500MHz shielded antenna.

Electromagnetic numerical simulation in heterogeneous media is essential to validate the geological interpretations. The GPR wave modelling is, in general, one-dimensional in the literature. Goodman and Nishimura [16] proposed a two-dimensional wave simulation method based on ray-tracing techniques. However, this approach suffers the disadvantages of ray methods, i.e., the impossibility of modelling the full wave field at all frequency ranges (e.g., the complete set of multiples and diffractions), and the generation of non-uniform dissipative waves at material interfaces (e.g., [17]). It is important to model the correct frequency dependence of the permittivity. At radar frequencies $(\approx 50 \mathrm{MHz}-1 \mathrm{GHz})$, various dielectric dispersion processes occur. In moist soils, the most important are ionic conductivity and relaxation effects. The relaxation produces an increase in attenuation with frequency, since the molecules begin to lag the applied field and increase the real effective conductivity. This phenomenon is well described by a Debye relaxation peak, having its analogy in the Zener rheological model (also called standard linear solid) used in visco elasticity (e.g., [17]). Moreover, at high frequencies, the response of free charges may lag the electric field and produce an out-of-phase component, contributing to the real effective permittivity. These phenomena, i.e., dielectric relaxation and out-of phase electric currents, are introduced into the Maxwell equations by means of time-domain permittivity and conductivity functions [6, 7].

\section{Field study}

As mentioned above, the target is a domestic pig cadaver buried at a depth of $1 \mathrm{~m}$. The pit was made in a ground with predominance of clay and loamy sands. Figure 1 shows a simplified scheme. Figure 2 shows pig carcass prepared for burial.

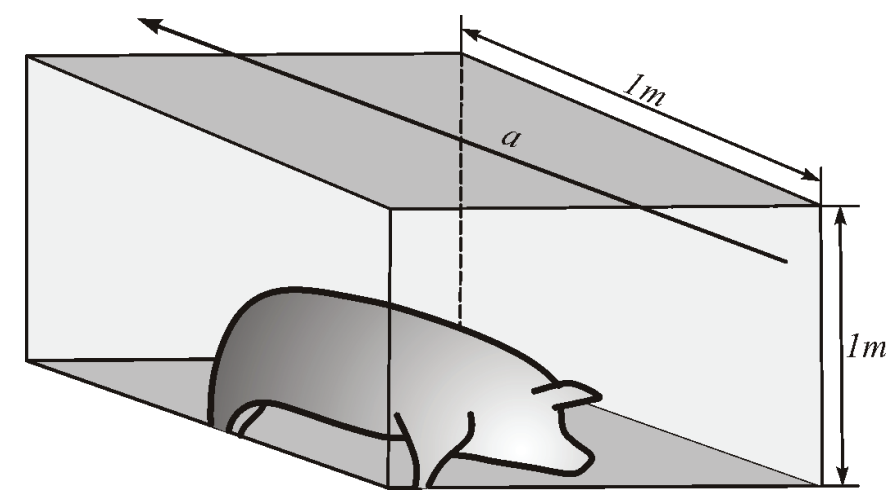

Fig. 1. Sketch of buried pig with an indicated direction of profiling. 


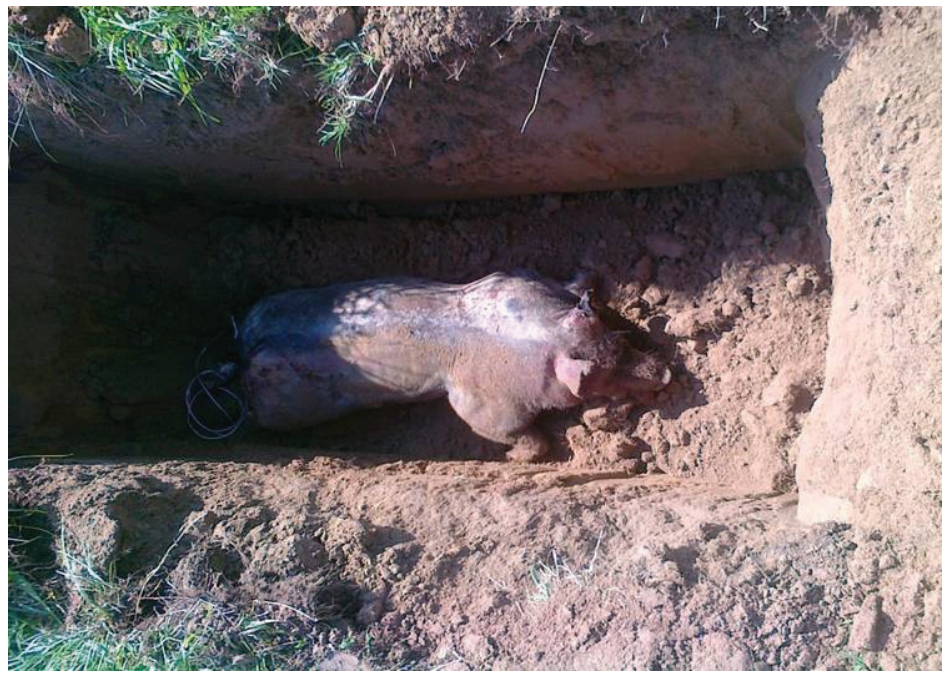

Fig. 2. The pig cadaver prepared for burial.

The measurements have been performed with a ProEx System GPR. Antennas of various designs and frequency ranges were used, from 100 to $800 \mathrm{MHz}$. In this work, only the results for the $500 \mathrm{MHz}$ antenna are presented. On the basis of resolution arguments, it can be shown that an antenna of such frequency is the optimal one for searching burial sites located at the depth of $2 \mathrm{~m}$ or less. A set of radar profiles of a length of approximately $10 \mathrm{~m}$ have been acquired. The data has been processed with the ReflexW software manufactured by the Sandmeier company.

\section{Modelling the electromagnetic field}

Figure 3 shows the model with a dimension of $2 \times 1.5 \mathrm{~m}$. The ellipse, with semi-axis of $0.5 \mathrm{~m}$ and $0.25 \mathrm{~m}$, represents the pig cadaver.

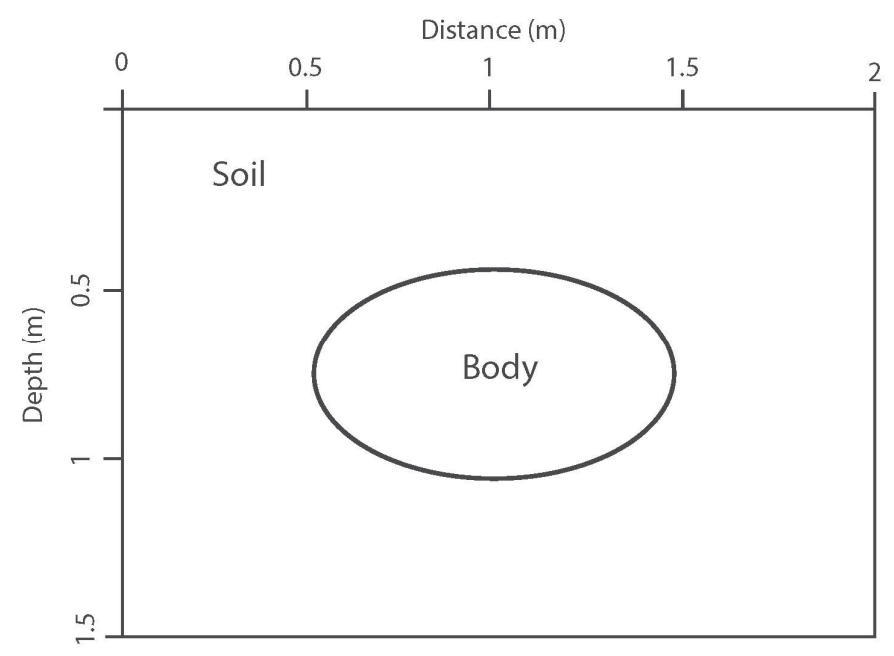

Fig. 3. Model representing a cross-section of a pig buried in soil. 
The electromagnetic properties are given in Table 1, where $\varepsilon_{r}$ and $\mu_{r}$ are the relative permittivity and magnetic permeability, respectively, and $\sigma$ is the electrical conductivity [18].

Table 1. Model electromagnetic properties.

\begin{tabular}{|c|c|c|c|}
\hline & $\boldsymbol{\varepsilon}_{\boldsymbol{r}}$ & $\boldsymbol{\sigma}(\mathbf{S} / \mathbf{m})$ & $\boldsymbol{\mu}_{\boldsymbol{r}}$ \\
\hline soil & 16 & 0.04 & 1 \\
\hline body & 50 & 0.8 & 1 \\
\hline
\end{tabular}

The pseudo-spectral Fourier method is used to obtain the synthetic electromagnetic field (radargrams). A detailed introduction to this method can be found in Carcione $[6,7,19]$ and Carcione et al. [20]. The model is discretized into $0.02 \mathrm{~m}$ cells with $135 \mathrm{x} 135$ grid points. The model is extended $0.35 \mathrm{~m}$ on the sides, top and bottom in order to include absorbingboundary conditions (suppression of the electromagnetic wave at the model boundaries to avoid wraparound). The simulations have a source time history applied to the horizontal electric current (a Ricker wavelet) with a central frequency of 500MHz.

\section{Results and analysis}

The field measurements were conducted with the ProEx georadar of the Swedish company MALA GeoScience. A set of profiles were acquired in the testing area, with the use of various antennas. In Figure 4, a radargram corresponding to the $500 \mathrm{MHz}$ antenna is displayed. During the field measurements the following parameters were assumed: number of samples: 730; number of stacks: 8 ; distance intervals $\Delta \mathrm{x}=0.02 \mathrm{~m}$.

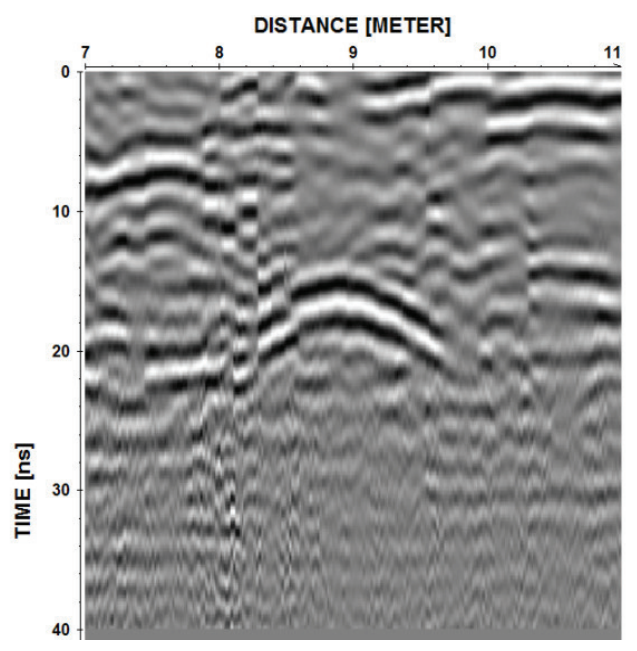

Fig. 4. Radargram recorded with the $500 \mathrm{MHz}$ antenna along the profile a (Figure 1).

The radargram presented in the further part of the article was subjected to standard digital signal processing in the ReflexW software of the German company SandmeierGeo (among the other procedures were applied: $t_{0}$ correction, background removal, subtracking average). As can be appreciated, there are events between 10 and $15 \mathrm{~ns}$ (the top of the body presumably) and a characteristic hyperbola at approximately $22 \mathrm{~ns}$ between 8.5 and 9.5 m horizontal distance, where the bottom of the pit is located. Somehow, these events correspond to the pig cadaver.

We have modelled the response with the above mentioned numerical algorithm. The 
radargrams obtained with the pseudo-spectral method are shown in Figure 5. Snapshots (not shown) indicate that a complicated interference pattern is produced by reverberations inside the body. The high dissimilar permittivity constants of the soil and the body (at $500 \mathrm{MHz}$ ) generates the strong reflection event, which originates at the top of body. However, the dissipation due to the high conductivity inside the body has damped the reflection coming from the bottom. As can be seen in Figure 5, there is practically no energy transmission below the body, contrary to the to the real case, where there is a strong event related to the bottom of the pit. This discrepancy may indicate that the wave loss inside the body is not so strong, meaning that the conductivity can be much lower, due to the presence of air or degradation of the medium. Then, we have performed another simulation with air replacing the pig. As is well known, air has a negligible conductivity, in practice a very high resistivity. Figure 6 shows the corresponding radargrams, where it can be seen that more events are present below the main hyperbola with apex at $12 \mathrm{~ns}$.

Further work may consider other interpretation tools. For example, Mazurkiewicz et al. [21] use artificial neuron networks to process data. The Multilayer Perceptron network is used, which is based on an empirically sized hidden layer, trained by wave propagation. The fundamental difficulty associated with the method of introducing information on the analysed GPR image is overcome by substituting the signal samples values (that can be many) with a parametric description obtained with a polynomial approximation [22]. These methods will be applied in a future work dealing with the present problem.

\section{Conclusions}

We have acquired GPR profiles above a pit containing a pig cadaver. The method shows that the surface radar can help detect the body, especially in simple geological condition (similar to described in article). To support the interpretation, we have performed numerical simulations with a full-wave direct modelling technique, based on the Fourier pseudospectral method. In order to obtain a good qualitative comparison order to enhance the reflections from the bottom of the pit. A too high conductivity implies an energy loss due to wave dissipation (due to ionic currents) and those events can hardly be seen. Low conductivity, on the contrary, implies a series of events from top to bottom of the pit, which show a better comparison with the real data.

This work was financed within the agreement numbers 11.11.140.645 and 15.11.140.474 (AGH University of Science and Technology, Faculty of Geology, Geophysics and Environmental Protection). 


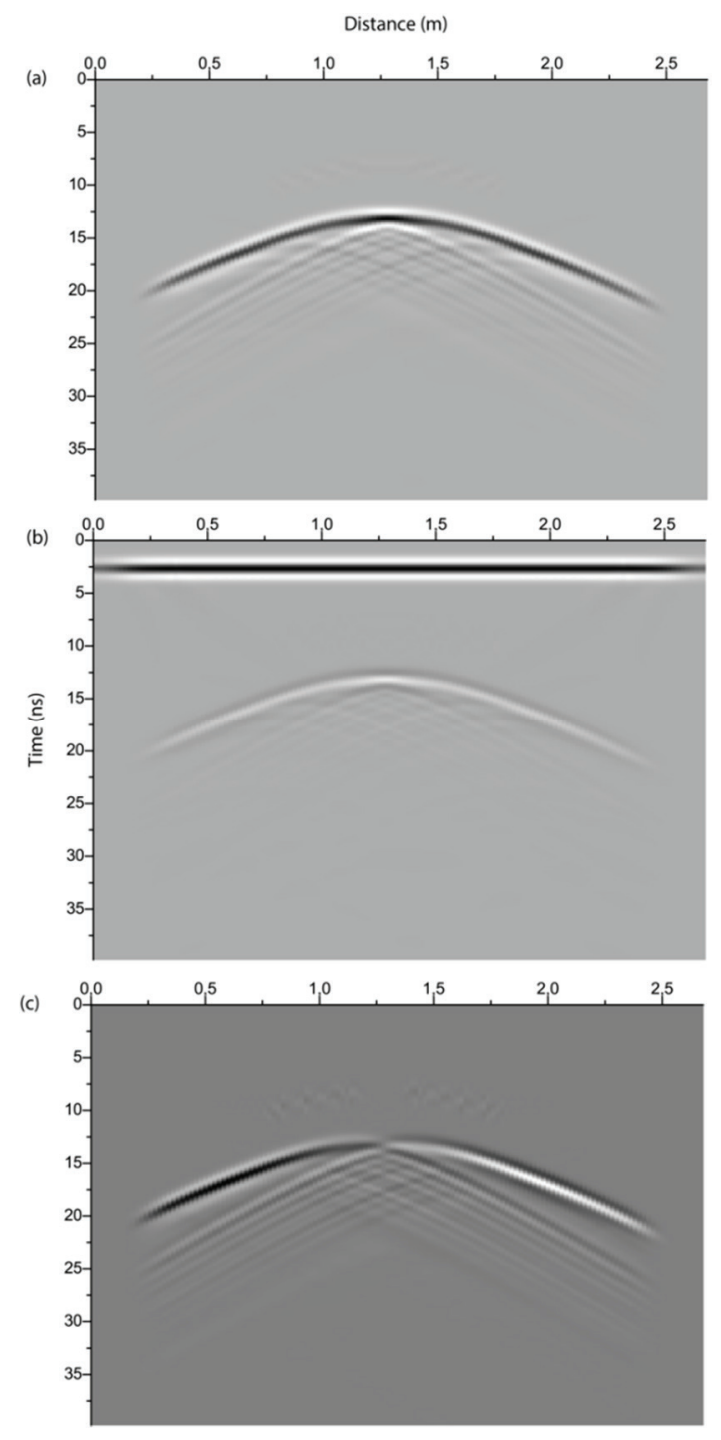

Fig. 5. Synthetic radargrams representing the magnetic field $H_{y}$ (a) and the horizontal and vertical electric fields $E_{x}(\mathrm{~b})$ and $E_{z}(\mathrm{c})$. The frequency of the radar is $500 \mathrm{MHz}$ (pseudo-spectral Fourier method, see Carcione (1996 a, b). 


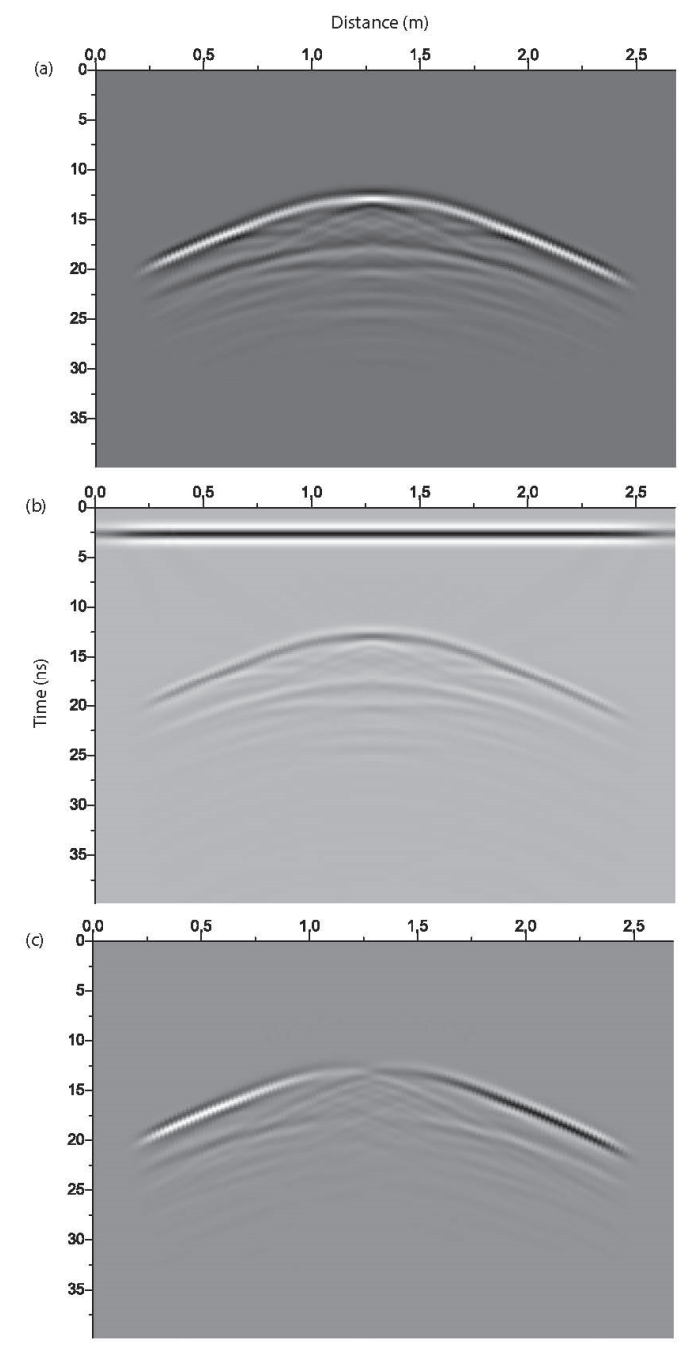

Fig. 6. Synthetic radargrams (as in Fig. 4), corresponding to a void instead of the pig.

\section{References}

1. H. M. Jol, Ground penetrating radar: theory and applications (Elsevier, 2009)

2. Ł. Ortyl, J. Karczewski, E. Mazurkiewicz, Importance of selecting parameters of georadar profiles in karst area, Proc. of 17th International Multidisciplinary Scientific Geoconference: Science and Technologies in Geology, Exploration and Mining., 173180 (Albena, Bulgaria, 29 June-5 July 2017)

3. S. Tomecka-Suchoń, Acta Geophys. 60, 386-398 (2012) doi: 10.2478/s11600-011-0019$\mathrm{z}$

4. M. de la Vega, A. Osella, E. Lascano, J. M. Carcione, Archaeol. Prospect. 12, 19-30 (2005) doi: 10.1002/arp.244

5. Z. Pilecki, J. Kłosiński, E. Pilecka, J. Karczewski, J. Ziętek, Wpływ zawodnienia osuwiska na rozpoznanie granic jego nieciagłości metodami falowymi. Gospod. Surowcami Min. 24, 427-444 (2008) 
6. J. M. Carcione, Geophysics, 61, 1664-1677 (1996) doi: 10.1190/1.1444085

7. J. M., Carcione, Geophys. Prospect. 44, 871-888 (1996) doi: 10.1111/j.13652478.1996.tb00178.x

8. J. A. Doolittle, N. F. Bellantoni, Journal of Archeological Science, 37, 941-949 (2010) doi:10.1016/j.jas.2009.11.027

9. J. J. Schultz, M. E. Collins, A. B. Falsetti, J. Forensic Sci. 51, 607-616 (2006) doi: 10.1111/j.1556-4029.2006.00129.x

10. J. K. Pringle, J. R. Jervis, J. D. Hansen, G. M. Jones, N. J. Cassidy, J. P. Casella, J. Forensic Sci. 57, 1467-1486 (2012) doi:10.1111/j.1556-4029.2012.02151.x

11. C. A. Dionne, D. K. Wardlaw, J. J. Schultz, Delineation and Resolution of Cementary Graves Using Conductivity Meter and Ground-Penetrating Radar. Technical Briefs in Historical Archeology 5, 20-30 (2010)

12. S. C. Buck, J. Forensic Sci., 48, 1-7 (2003) doi: 10.1520/JFS2002165

13. T. Golebiowski, Environment Engineering, 24, 39-53 (2015) doi: 10.4467/2353737XCT.15.225.4611

14. T. Golebiowski, Acta Geophys. 54, 413-429 (2006) doi: 10.2478/s11600-006-0027-6

15. H. Marcak, T. Golebiowski, Computer simulation of hydrocarbon flow and wave field for interpretation GPR measurements in contaminated sites. Proc. of 18th Annual Meeting of SAGEEP, Symposium on the Application of Geophysics to Engineering and Environmental Problems, 837-846, (Atlanta, Georgia, 3-7 April 2005)

16. D. Goodman, Y. Nishimura, A ground-radar view of Japanese burial mounds. Antiquity 67, 349-354 (1993) doi: 10.1017/S0003598X00045403

17. J. M. Carcione, Wave Fields in Real Media. Theory and numerical simulation of wave propagation in anisotropic, an elastic, porous and electromagnetic media (Elsevier, 2014)

18. J. Modroo, G. R. Olhoeft, Ground penetrating radar location of buried avalanche victims, Proc. of the 2004 International Snow Science Workshop, (Jackson Hole, Wyoming 19-24 Sep. 2004)

19. J. M. Carcione, Geophysics 75, 53-56 (2010) doi: 10.1190/1.3509472

20. J. M. Carcione, G. Lenzi, S. Valle, Geophys. Prospect. 47, 1015-1029 (1999) doi: 10.1046/j.1365-2478.1999.00151.x

21. E. Mazurkiewicz, S. Tomecka-Suchoń, R. Tadeusiewicz, Applied Artificial Intelligence 30, 844-860 (2016) doi: 10.1080/08839514.2016.1274250

22. R. Tadeusiewicz, Arch. Min. Sci. 60, 971-984 (2015) doi: 10.1515/amsc-2015-0064 